This item was submitted to Loughborough's Research Repository by the author.

Items in Figshare are protected by copyright, with all rights reserved, unless otherwise indicated.

\title{
Sociocultural risk factors for compulsive exercise: a prospective study of adolescents
}

PLEASE CITE THE PUBLISHED VERSION

http://dx.doi.org/10.1002/erv.2309

\section{PUBLISHER}

(c) Wiley \& Eating Disorders Association

\section{VERSION}

AM (Accepted Manuscript)

\section{PUBLISHER STATEMENT}

This work is made available according to the conditions of the Creative Commons Attribution-NonCommercialNoDerivatives 4.0 International (CC BY-NC-ND 4.0) licence. Full details of this licence are available at: https://creativecommons.org/licenses/by-nc-nd/4.0/

\section{LICENCE}

CC BY-NC-ND 4.0

\section{REPOSITORY RECORD}

Goodwin, Huw, Emma Haycraft, and Caroline Meyer. 2019. "Sociocultural Risk Factors for Compulsive Exercise: A Prospective Study of Adolescents”. figshare. https://hdl.handle.net/2134/15734. 
Sociocultural risk factors for compulsive exercise:

A prospective study of adolescents

\author{
Huw Goodwin PhD ${ }^{1}$ \\ Emma Haycraft $\mathrm{PhD}^{1^{*}}$ \\ Caroline Meyer PhD ${ }^{1}$
}

${ }^{1}$ Loughborough University Centre for Research into Eating Disorders

Loughborough University, Leicestershire, UK

* Address correspondence to: Dr Emma Haycraft, Loughborough University Centre for Research into Eating Disorders, School of Sport, Exercise and Health Sciences, Loughborough University, Leicestershire LE11 3TU, UK

Email: e.haycraft@lboro.ac.uk; Tel.: +44(0)1509 228160.

RUNNING HEAD: compulsive exercise 


\title{
Sociocultural risk factors for compulsive exercise:
}

\section{A prospective study of adolescents}

\begin{abstract}
The risk factors for compulsive exercise are unknown. This study aims to explore longitudinal sociocultural risk factors for compulsive exercise, using a 12 month prospective design. A sample of 332 male and female adolescents (aged 13-15 years at baseline) completed self-report measures of sociocultural risk factors and compulsive exercise at baseline and eating disorder psychopathology and compulsive exercise at 12-month follow-up assessment. Hierarchical regressions found that family and peer messages to become more muscular predicted compulsive exercise in boys, whilst feeling pressure from the media to be thin was a significant predictor of compulsive exercise in girls. These relationships remained significant when controlling for eating disorder psychopathology, but became nonsignificant when initial levels of compulsive exercise were entered into the model. The findings suggest that sociocultural risk factors may contribute to the development of compulsive exercise but future research should utilise a younger sample and employ a longer follow-up period to identify true longitudinal effects.
\end{abstract}

Keywords: Environment; Eating Disorders; Risk Factors; Media Pressure; Muscularity. 


\section{Sociocultural risk factors for compulsive exercise:}

\section{A prospective study of adolescents}

Exercise is predominantly a healthy behaviour that has positive psychological and physical consequences (Warburton, Whitney Nicol, \& Bredin, 2006). However, it has been reported anecdotally and empirically that some individuals will develop a compulsion to exercise, which can negatively affect the individual's quality of life (Mond, Hay, Rodgers, \& Owen, 2006), leading to a negative state of psychological and physical harm (Iannos \& Tiggemann, 1997; Meyer, Taranis, Goodwin, \& Haycraft, 2011). Although the terminology used to describe this potentially pathological behaviour has varied in the literature, it is arguably most appropriate to describe it as a compulsion (see Meyer \& Taranis, 2011). Compulsive exercise typically describes a routine-like pattern of exercise, often performed despite possible negative consequences, with compulsive exercisers reporting intense feelings of guilt at any missed exercise sessions (Meyer et al., 2011). It has been likened to a pathological behavioural addiction (Griffiths, 1997), although it has also been associated with obsessive-compulsiveness (Gulker, Laskis, \& Kuba, 2001; Yates, 1991). The motivation to exercise for compulsive exercisers is commonly related to eating, weight and shape concerns (Lipsey, Barton, Hulley, \& Hill, 2006). Indeed, compulsive exercise is a relatively widespread symptom in clinical eating disorder patients (Davis, 1997; Shroff et al., 2006).

Among eating disorder patients, compulsive exercise has been shown to prolong treatment and to increase the chance of relapse (Solenberger, 2001; Strober, Freeman, \& Morrell, 1997). Premorbid excessive activity levels have also been linked to the compulsive exercising seen in individuals during the acute phase of their eating disorder (Davis et al., 1997). Therefore, it is important to understand the aetiology of compulsive exercise and to identify potential risk factors that could lead to its development. 
The majority of research into compulsive exercise has focused on the associated psychological characteristics. For example, Penas-Lledo, Vaz Leal, and Waller (2002) found an association between compulsive exercise and anxiety and depression. Further, Gulker and colleagues (2004) demonstrated that compulsive exercisers report greater levels of obsessive-compulsiveness than their noncompulsive exercising counterparts. Among adolescents, a more recent investigation reported that perfectionism and obsessive-compulsiveness predicted compulsive exercise cognitions cross-sectionally (Goodwin, Haycraft, Willis, \& Meyer, 2011). However, despite there being research into the psychological correlates of compulsive exercise, there has been minimal work into the environmental factors associated with compulsive exercise.

One of the few studies to examine the environmental factors potentially linked to compulsive exercising was by White and Halliwell (2010). In their study, they tested a sociocultural model of excessive exercise in male and female adolescents. Their results suggested that sociocultural pressures to lose weight and build muscle predicted compulsive exercise in adolescent boys and girls. However, this relationship was fully mediated by an investment in appearance and body image disturbance. Therefore, the sociocultural risk factors for their measure of compulsive exercise did not demonstrate specificity for compulsive exercise, and instead appeared to be risk factors for general disordered eating attitudes, namely body dissatisfaction. Additionally, their investigation was a cross-sectional study and needs to be replicated using a prospective design.

A more recent investigation of compulsive exercise found, after controlling for Body Mass Index (BMI) and disordered eating, that feeling pressure from the media to be thin was associated with greater compulsive exercise for both boys and girls, whilst among boys only, messages to become more muscular was also associated with increased compulsive exercise (Goodwin, Haycraft, \& Meyer, 2011). This study 
by Goodwin and colleagues was cross-sectional and thus requires replication and extension by using a longitudinal design.

In summary, sociocultural factors have been implicated in the development of disordered eating in adolescents (Field et al., 2001), and have also been associated cross-sectionally with compulsive exercise (Goodwin, Haycraft, \& Meyer, 2011; White \& Halliwell, 2010). However, no studies have considered the specific sociocultural risk factors for compulsive exercise longitudinally. It is useful to study this in an adolescent population as this age period of pubertal development has an impact on body image (Siegel, Yancey, Aneshensel, \& Schuler, 1999), as well as represents the age period of greatest risk for the development of eating disorders (StriegelMoore \& Bulik, 2007).

This study therefore examines the sociocultural risk factors identified in Goodwin, Haycraft, and Meyer's (2011) investigation (i.e., media pressure to be thin, messages to be more muscular), assessing their predictive role on compulsive exercise, whilst accounting for eating disorder psychopathology (given the findings of White \& Halliwell, 2010). It is hypothesised that these sociocultural risk factors will positively predict compulsive exercise, irrespective of eating disorder psychopathology.

\section{METHOD}

\section{$\underline{\text { Participants and Procedure }}$}

Following institutional ethical review board approval, five schools in the United Kingdom agreed to participate in research into adolescent exercise and eating attitudes (nine schools had been invited). Questionnaire packs were sent to those schools who had agreed to participate, resulting in an initial total sample of 828 adolescents. Questionnaire packs were completed at baseline assessment (T1) during a school class period by all pupils aged between 13 and 15 years old. The 
completed packs were returned to the research team. Identification codes were assigned to each pack to ensure that the individual could be matched at the follow-up assessment. Follow-up assessment took place 12 months later (T2), using the same procedure.

The final sample used for the current study was 332 adolescents (boys $n=$ 146 , girls $n=186$ ) from five schools ( $n$ per school $=201,30,37,53,11$ ). At $T 1$, the mean age of participants was 13.97 years $(S D=0.69$; range $13-15$ years), and $97.8 \%$ of the sample reported their nationality as British. Ethnicity was predominantly White British (93.8\%). Self-reported Body Mass Index (BMI) for boys was 20.01 (SD $=3.38)$ at $\mathrm{T} 1$ and $21.18(\mathrm{SD}=3.08)$ at $\mathrm{T} 2$. For girls, the mean BMI was $19.73(\mathrm{SD}=$ 2.79) at $\mathrm{T} 1$ and $21.03(\mathrm{SD}=3.26)$ at $\mathrm{T} 2$. These means were converted into age and gender adjusted BMI z scores (Child Growth Foundation, 1996). At T1, the mean BMI $z$ score for boys was $0.25(S D=1.28)$ and for girls it was $-0.01(S D=1.03)$. At $T 2$, the BMI $z$ score mean for boys was $0.56(S D=1.06)$ and was $0.25(S D=1.05)$ for girls. These BMI z scores all represent generally healthy weights.

\section{$\underline{\text { Measures }}$}

For the purposes of this study, background information (age, gender, nationality, height and weight) was gathered before the following established questionnaires were administered:

Time Point 1 (T1):

Compulsive Exercise Test (CET; Taranis, Touyz, \& Meyer, 2011). The CET measures an individual's compulsivity towards exercise, and this measure was used as the outcome variable in the current study. A CET Total score is summed from the mean averages of the five subscales: Avoidance and Rule-Driven Behaviour, Weight Control Exercise, Mood Improvement, Lack of Exercise Enjoyment, and Exercise Rigidity. Respondents indicate their level of compulsive exercise on a 6-point Likert scale for each of the 24 questions, ranging from " 0 - never true" to " 5 - always true". 
Greater scores represent greater levels of compulsive exercise. The CET has been psychometrically tested for use in an adolescent sample, demonstrating good discriminant and divergent validity (Goodwin, Haycraft, Taranis, \& Meyer, 2011). The Cronbach's alpha reliability value for the current sample was .88 for T1 CET Total score (.89 for boys; .88 for girls).

Modified Perceived Sociocultural Influences on Body Image and Body Change Questionnaire (mSCIQ; McCabe \& Ricciardelli, 2001a). The Sociocultural Influences on Body Image and Body Change Questionnaire was modified in a previous investigation (Meesters, Muris, Hoefnagels, \& van Gemert, 2007), and the modified version was used in this study at T1. The mSCIQ assessed perceived encouragement from the respondent's father, mother, and best friend, to become more muscular. To assess these messages, items relating to becoming more muscular (e.g. "Does your father encourage you to become more muscular?") were averaged to form a subscale (mSCIQ More Muscular). Higher scores on the scale indicate a greater sociocultural influence to become more muscular. Cronbach's alphas demonstrated good reliability for this scale in the current sample (total sample $=.77 ;$ boys $=.77 ;$ girls $=.62$ ) .

Perceived Sociocultural Pressure Scale (PSPS; Stice \& Bearman, 2001). The PSPS was used at T1 in the current study. The PSPS measures the degree of pressure to be thin that the respondent feels from sociocultural sources. Following on from the cross-sectional findings of Goodwin, Haycraft, and Meyer (2011), the media pressure to be thin scale was used (e.g. "I've noticed a strong message from the media to have a thin body"). Respondents are given a 5-point Likert scale that is anchored with " $1=$ none" and " $5=$ a lot", with higher scores representing greater perceived pressure. The PSPS has been reliably used with adolescents (e.g., Presnell, Bearman, \& Stice, 2004; Stice \& Whitenton, 2002). The Cronbach's alpha reliability statistic for this subscale was .85 (.72 for boys; .87 for girls).

Time Point 2 (T2): 
Eating Disorder Inventory-2 (EDI-2; Garner, 1991). The EDI-2 subscales of Drive for Thinness, Bulimia and Body Dissatisfaction were used to assess eating disorder psychopathology at follow-up. A total eating disorder psychopathology score (EDI Total) was formed by summing the three subscale totals, which has been performed in previous research (e.g., Adkins \& Keel, 2005). Higher EDI Total scores equate to greater levels of eating disorder psychopathology. The EDI has been widely cited in the literature (e.g., Anton, Perri, \& Riley, 2000; Hart \& Kenny, 1997; Kostanski \& Gullone, 1998), including with adolescents (e.g., Grylli, Hafferl-Gattermayer, Schober, \& Karwautz, 2004). The Cronbach's alpha value for EDI Total was .91 for the current sample (.82 for boys; .91 for girls).

Compulsive Exercise Test (CET; Taranis, Touyz, \& Meyer, 2011). The CET was also completed at $\mathrm{T} 2$, and represented the primary outcome measure in the current investigation. The Cronbach's alpha reliability value for the current sample was .88 for T2 CET Total score (.90 for boys; .85 for girls).

\section{$\underline{\text { Data Analysis }}$}

At the first time point, 828 adolescents completed questionnaires (see Goodwin, Haycraft, \& Meyer, 2011, for sample description), then 332 of this sample completed questionnaires at the follow-up (T2), which is the sample reported in the current investigation. Although drop-outs were primarily due to classroom changes and other school commitments, rather than at the individual level, attrition analysis (Mann Whitney $U$ test) was still performed. This revealed that drop-outs $(n=496)$ were not significantly different to the retained sample on any of the study measures at T1: mSCIQ More Muscular $(z=1.90, p>.05)$; PSPS Media $(z=1.23, p>.05)$; T1 CET Total $(z=1.28, p>.05)$. This suggests there was no systematic bias to sample recruitment using the longitudinal design. 
All analyses were conducted separately for boys and girls to further replicate the cross-sectional findings of Goodwin, Haycraft, and Meyer (2011), as well as due to sociocultural influences on eating disorder psychopathology being found to be gender-specific (Field et al., 2001). This decision was supported by preliminary tests of difference (Mann Whitney $U$ ) showing significant differences between boys and girls on almost all study variables (Table 1).

Goodwin, Haycraft, and Meyer (2011) found that BMI was not a significant predictor of compulsive exercise. Correlations (Spearman's rho) conducted in the current sample between T1 BMI z scores and the outcome variable (T2 CET Total) also revealed non-significant findings in boys and girls $(p>.05)$. In addition, it must be noted that BMI data in the current investigation was limited by high rates of missing data. Therefore, for the above reasons, BMI z scores were not entered into the regression models in the current investigation.

The study's hypotheses were tested using hierarchical multiple regressions, using a bootstrap method (using the Statistical Package for Social Scientists' bootstrap function based on 1000 bootstrap samples) to examine significant unique contributions of predictor variables. In the first step of the regression model, the hypothesised sociocultural factors were entered to identify their significant prediction of compulsive exercise at 12-month follow-up (T2 CET Total). The follow-up eating psychopathology measure (EDI Total) was then entered in the second step to identify whether or not the sociocultural predictors retained any significant unique contribution to T2 CET Total when entered simultaneously with a follow-up measure of eating psychopathology. Finally, baseline CET (T1 CET Total) was entered in the third step to establish whether any earlier significant contributions would remain, to confirm longitudinal associations. Significance was set at $p<.05$ for all analyses.

\section{RESULTS}

\section{Characteristics of the sample}


The means and standard deviations, and a test of difference between boys and girls, of all study variables can be seen in Table 1. There were significant differences between boys and girls on all variables. Specifically, boys scored significantly higher than girls on the mSCIQ More Muscular subscale. Girls scored significantly higher than boys on PSPS Media, EDI Total, and T2 CET Total. The T2 CET Total means represent low to mid-point scoring averages ("sometimes true of me") for both boys and girls.

TABLE 1 ABOUT HERE

\section{$\underline{\text { Sociocultural predictors of compulsive exercise }}$}

Boys

Preliminary single predictor regressions found that PSPS Media was not a significant predictor of T2 CET Total $(p>.05)$. Therefore, this variable was not used in any further analyses among boys. The first step of the primary hierarchical regression (see Table 2) was significant $\left(F_{(1,138)}=13.092, p<.001\right)$, with $\mathrm{mSCIQ}$ Muscular predicting $8 \%$ of the T2 CET Total variance (Adjusted $\mathrm{R}^{2}$ ). The second step (where EDI Total was added to the model), did not produce a significant $\mathrm{R}^{2}$ change $\left(R^{2}\right.$ change $\left.=.02, p>.05\right)$, although the model remained significant overall $\left(F_{(2,137)}=\right.$ 7.79, $\mathrm{p}<.001$ ). The final step (where T1 CET Total was added to the model) resulted in a significant $R^{2}$ change, accounting for an additional $34 \%$ of the variance alone $\left(R^{2}\right.$ change $=.34, p<.001)$. The final model remained significant overall $\left(F_{(3,136)}=35.175\right.$, $p<.001$ ) and accounted for $42 \%$ of T2 CET Total variance (Adjusted $\mathrm{R}^{2}$ ). Bootstrapped coefficients (seen in Table 2) demonstrated that mSCIQ Muscular was a significant unique predictor at the first and second step of the model, but became non-significant when baseline CET Total (T1 CET Total) was added to the model in the third step. T1 CET Total was also a significant unique predictor. The EDI Total 
variable did not significantly predict T2 CET Total in either the second or third steps of the model.

TABLE 2 ABOUT HERE

Girls

Preliminary single predictor regressions found that $\mathrm{mSClQ}$ Muscular was not a significant predictor of T2 CET Total $(p>.05)$. Therefore, this predictor was not used in any further analyses among girls, and PSPS Media was the only sociocultural predictor entered into the subsequent regression analysis model.

The hierarchical regression result can be seen in Table 3. The regression found that the first step, with just PSPS Media as a predictor of T2 CET Total, was significant $\left(F_{(1,180)}=32.475, p<.001\right)$, accounting for $15 \%$ of the variance of the outcome (Adjusted $\mathrm{R}^{2}$ ). The addition of EDI Total in the second step led to a significant $R^{2}$ change of $9 \%\left(R^{2}\right.$ change $\left.=.09 ; F_{\text {change }}(1,179)=20.353, p<.001\right)$, and the model remained significant $\left(F_{(2,179)}=28.16, p<.001\right)$. The final step of adding in baseline CET Total (T1 CET Total) also led to a significant increase in $\mathrm{R}^{2}$, accounting for an additional $15 \%$ of variance $\left(R^{2}\right.$ change $=.15 ; F$ change $e_{(1,178)}=44.304, p$ $<.001)$. The final model in total was significant $\left(F_{(3,178)}=38.083, p<.001\right)$ and accounted for $38 \%$ of outcome variance (Adjusted $\mathrm{R}^{2}$ ). Bootstrapped coefficients (seen in Table 3) showed that PSPS Media was a significant unique predictor at both the first and second steps, remaining significant when EDI Total was added to the model. EDI Total was also a significant unique predictor at the second and third steps. Finally, T1 CET Total was a significant unique predictor of outcome. PSPS Media became non-significant when T1 CET Total was included in the model. 


\section{DISCUSSION}

The current study aimed to examine the relationship between sociocultural factors, eating disorder psychopathology and compulsive exercise in adolescents, using a longitudinal design. Overall, the results demonstrated that for both boys and girls, sociocultural factors were significantly associated with compulsive exercise at 12-month follow-up, irrespective of eating psychopathology, but this association disappeared when initial baseline levels of compulsive exercise were taken into account.

The results among boys were in accordance with the cross-sectional findings of Goodwin, Haycraft, and Meyer (2011), as messages to become more muscular (from parents and peers) significantly predicted compulsive exercise. This may suggest that boys who perceive more messages from close others to increase muscularity may be more susceptible to developing a compulsive drive to exercise, although this was not fully supported when initial levels of compulsive exercise were already taken into account. Nonetheless, the results suggested that the effect of these perceived messages on subsequent compulsive exercise remained even when accounting for eating psychopathology, which partly disputes previous investigations of adolescents (White \& Halliwell, 2010).

The failure of eating disorder psychopathology to be significantly related to compulsive exercise in the current sample of boys suggests that a compulsive drive to exercise may represent something separate from more generalised eating disorder psychopathology. Alternatively, it could be that the constructs assessed by the EDI measure here (Drive for Thinness, Bulimia, Body Dissatisfaction), may not be achieved via the use of compulsive exercising, but rather more through dieting behaviours. This relationship between eating disorder psychopathology and compulsive exercise in boys warrants further investigation. The results from the 
current study do support previous research which has found that adolescent boys' peer groups are influential in shaping boys' body image and dieting behaviours (Muris, Meesters, Van de Blom, \& Mayer, 2005). Therefore, compulsive exercise prevention work in adolescents should look to target environments which encourage muscular physiques among boys, in order to reduce the impact that these messages may have on the cognitions and behaviours of boys.

The results for girls in the current study identified perceived pressures from the media to be thin as a significant predictor of compulsive exercise, although with the finding for boys, this prediction lost significance when initial levels of compulsive exercise were accounted for in the model. Nonetheless, the relationship between media pressures and possible weight control practices is in agreement with the general literature which has found that media influences on adolescent girls can increase the internalisation of the 'thin ideal' of Western culture (Field et al., 2001; Knauss, Paxton, \& Alsaker, 2007), and can lead to an increase in the desire for thinness (Levine, Smolak, \& Hayden, 1994). This pressure for achieving thinness in the current sample could have led to an increase in the compulsivity to exercise either directly, or through an increase in eating disorder psychopathology. This supports the cross sectional study of Goodwin, Haycraft, and Meyer (2011), which found that feeling pressure from the media to be thin was associated with compulsive exercise at 13-15 years old. The current finding that the media's influence was a significant predictor of only girls', and not boys', compulsive exercise, also confirms previous research which found that girls' weight control and body change strategies were more influenced by media than was reported by their male counterparts (McCabe \& Ricciardelli, 2001). This gender difference is possibly due to the stronger female 'ideal' that is portrayed in Western media, in contrast to the less bodyorientated male 'ideal', although this warrants further investigation.

There are some important practical implications of these findings. Professionals working with adolescents need to be cognisant of the pressure from 
their family and peers that boys may be feeling to be more muscular. This is regardless of their actual weight, and indeed could lead to harmful compulsive exercise cognitions. Therefore, compulsive exercise (or more general eating disorder) prevention and early intervention work among boys should perhaps identify and attempt to reduce any excessive pressures (or bullying) around boys' muscular physique. Among girls, it would appear that prevention work needs to target their susceptibility to taking on media messages to be thin, and this could have beneficial preventative effects on their compulsive exercise cognitions. Most importantly from these longitudinal findings, though, is that the overwhelming association between compulsive exercise measured at baseline and compulsive exercise measured at twelve-month follow-up suggests that if an adolescent boy or girl is displaying compulsive exercise cognitions and/or behaviours, then it warrants exploration and possible intervention, as it appeared to be maintained over time in this current sample, and thus represents a key risk factor for future levels of compulsive exercise.

There were several limitations of this study. A key problem was that the lack of completed BMI data prevented this potentially confounding variable from being included in the analyses. Therefore, future research should aim to replicate these findings with larger samples and with objective measures of body weight and height. An additional limitation was that the length of follow-up was only one year. Although the 12-month follow-up used in the current study was greater than other longitudinal investigations of adolescent eating and exercise attitudes (e.g., Presnell et al., 2004), it could have been that the length of time was still not long enough to identify noticeable changes in compulsive exercising. Therefore, a longer follow-up period is suggested for future studies to identify whether sociocultural risk factors can predict more distal eating disorder psychopathology and compulsive exercise. Finally, a key limitation of these findings was the lack of significance found when initial levels of compulsive exercise were included in the prediction model. This suggests that these sociocultural factors may already be too closely tied to compulsive exercise at the 
baseline age of 13-15 years old and therefore, future research needs to study a younger age group, potentially at pre-pubertal age, to identify true longitudinal predictors of compulsive exercise.

In summary, this is the first study to longitudinally examine sociocultural risk factors for compulsive exercise. The findings suggest that family and peer messages to become more muscular could be a risk factor for compulsive exercise in boys, whilst a pressure from the media to be thin could be a risk factor for compulsive exercise in girls. However, the fact that these risk factors disappear when initial compulsive exercise is accounted for suggests that further research should replicate the current study using a younger sample and with a greater time period between baseline assessment and follow-up. 


\section{References}

Adkins, E. C., \& Keel, P. K. (2005). Does "excessive" or "compulsive" best describe exercise as a symptom of bulimia nervosa? International Journal of Eating Disorders, 38, 24-29.

Anton, S. D., Perri, M. G., \& Riley, J. R. (2000). Discrepancy between actual and ideal body images. Impact on eating and exercise behaviors. Eating Behaviors, $1,153-160$.

Baron, R. M., \& Kenny, D. A. (1986). The moderator-mediator variable distinction in social psychological research: Conceptual, strategic, and statistical considerations. Journal of Personality and Social Psychology, 51, 1173-1182.

Child Growth Foundation. (1996). Cross Sectional Stature and Weight Reference Curves for the UK. London, United Kingdom: Child Growth Foundation.

Davis, C. (1997). Eating disorders and hyperactivity: A psychobiological perspective. Canadian Journal of Psychiatry, 42, 168-175.

Davis, C., Katzman, D. K., Kaptein, S., Kirsh, C., Brewer, H., Kalmbach, K...\& Kaplan, A. S. (1997). The prevalence of high level exercise in the eating disorders: Etiological implications. Comprehensive Psychiatry, 38, 321-326.

Field, A. E., Camargo, C. A., Taylor, C. B., Berkey, C. S., Roberts, S. B., \& Colditz, G. A. (2001). Peer, parent, and media influences on the development of weight concerns and frequent dieting among preadolescent and adolescent girls and boys. Pediatrics, 107, 54-60.

Garner D. M. (1991). Eating Disorder Inventory-2: Professional Manual. Odessa, Fla, Psychological Assessment Resources.

Goodwin, H., Haycraft, E., \& Meyer, C. (2011). Sociocultural correlates of compulsive exercise: Is the environment important in fostering a compulsivity towards exercise among adolescents? Body Image, 8, 390-395. 
Goodwin, H., Haycraft, E., Taranis, L., \& Meyer, C. (2011). Psychometric evaluation of the Compulsive Exercise Test (CET) in an adolescent population: links with eating psychopathology. European Eating Disorders Review, 19, 269-279.

Goodwin, H., Haycraft, E., Willis, A., \& Meyer, C. (2011). Compulsive exercise: The role of personality, psychological morbidity, and disordered eating. International Journal of Eating Disorders, 44, 655-660.

Griffiths, M. (1997). Exercise addiction: A case study. Addiction Research \& Theory, 5, 161-168.

Grylli, V., Hafferl-Gattermayer, A., Schober, E., \& Karwautz, A. (2004). Prevalence and clinical manifestations of eating disorders in Austrian adolescents with type-1 diabetes. Wien Klin Wochenschr, 116/7-8, 230-234.

Gulker, M. G., Laskis, T. A., \& Kuba, S. A. (2001). Do excessive exercisers have a higher rate of obsessive-compulsive symptomatology? Psychology, Health \& Medicine, 6, 387-398.

Hart, K., \& Kenny, M. E. (1997). Adherence to the Super Woman ideal and eating disorder symptoms among college women. Sex Roles, 36, 461-478.

Iannos, M., \& Tiggemann, M. (1997). Personality of the excessive exerciser. Personality and Individual Difference, 22, 775-778.

Knauss, C., Paxton, S. J., \& Alsaker, F. D. (2007). Relationships amongst body dissatisfaction, internalisation of the media body ideal and perceived pressure from media in adolescent boys and girls. Body Image, 4, 353-360.

Kostanski, M., \& Gullone, E. (1998). Adolescent body image dissatisfaction: relationships with self-esteem, anxiety, and depression controlling for body mass. Journal of Child Psychology and Psychiatry, 39, 255-262.

Levine, M. P., Smolak, L., \& Hayden, H. (1994). The relation of sociocultural factors to eating attitudes and behaviors among middle school girls. The Journal of Early Adolescence, 14, 471-490. 
Lipsey, Z., Barton, S. B., Hulley, A., \& Hill, A. J. (2006). "After a workout..." Beliefs about exercise, eating and appearance in female exercisers with and without eating disorder features. Psychology of Sport and Exercise, 7, 425-436.

McCabe, M. P., \& Ricciardelli, L. A. (2001a). The structure of the perceived sociocultural influences on body image and body change questionnaire. International Journal of Behavioral Medicine, 8, 19-41.

McCabe, M. P., \& Ricciardelli, L. A. (2001b). Parent, peer, and media influences on body image and strategies to both increase and decrease body size among adolescent boys and girls. Adolescence, 36, 225-240.

Meesters, C., Muris, P., Hoefnagels, C., \& van Gemert, M. (2007). Social and family correlates of eating problems and muscle preoccupation in young adolescents. Eating Behaviors, 8, 83-90.

Meyer, C., \& Taranis, L. (2011). Exercise in the eating disorders: Terms and definitions. European Eating Disorders Review, 19, 169-173.

Meyer, C., Taranis, L., Goodwin, H., \& Haycraft, E. (2011). Compulsive exercise and eating disorders. European Eating Disorders Review, 19, 174-189.

Mond, J. M., Hay, P. J., Rodgers, B., \& Owen, C. (2006). An update on the definition of "excessive exercise" in eating disorders research. International Journal of Eating Disorders, 39, 147-153.

Muris, P., Meesters, C., Van de Blom, W., \& Mayer, B. (2005). Biological, psychological, and sociocultural correlates of body change strategies and eating problems in adolescent boys and girls. Eating Behaviors, 6, 11-22.

Penas-Lledo, E., Vaz Leal, F. J., \& Waller, G. (2002). Excessive exercise in anorexia nervosa and bulimia nervosa: Relation to eating characteristics and general psychopathology. International Journal of Eating Disorders, 31, 370-375.

Presnell, K., Bearman, S. K., \& Stice, E. (2004). Risk factors for body dissatisfaction in adolescent boys and girls: A prospective study. International Journal of Eating Disorders, 36, 389-401. 
Shroff, H., Reba, L., Thornton, L. M., Tozzi, F., Klump, K. L., Berrettin, W. H...\& Bulik, C. M. (2006). Features associated with excessive exercise in women with eating disorders. International Journal of Eating Disorders, 39, 454-461.

Siegel, J. M., Yancey, A. K., Aneshensel, C. S., \& Schuler, R. (1999). Body image, perceived pubertal timing, and adolescent mental health. Journal of Adolescent Health, 25, 155-165.

Solenberger, S. (2001). Exercise and eating disorders: A 3-year inpatient hospital record analysis. Eating Behaviours, 2, 151-168.

Stice, E., \& Bearman, S. K. (2001). Body image and eating disturbances prospectively predict growth in depressive symptoms in adolescent girls: A growth curve analysis. Developmental Psychology, 37, 597-607.

Stice, E., \& Whitenton, K. (2002). Risk factors for body dissatisfaction in adolescent girls: A longitudinal investigation. Developmental Psychology, 38, 669-678.

Striegel-Moore, R. H., \& Bulik, C. M. (2007). Risk factors for eating disorders. American Psychologist, 62, 181-198.

Strober, M., Freeman, R., \& Morrell, W. (1997). The long-term course of severe anorexia nervosa in adolescents: Survival analysis of recovery, relapse, and outcome predictors over $10-15$ years in a prospective study. International Journal of Eating Disorders, 22, 339-360.

Taranis, L., Touyz, S., \& Meyer, C. (2011). Disordered eating and exercise: Development and preliminary validation of the Compulsive Exercise Test (CET). European Eating Disorders Review, 19, 256-268.

Warburton, D. E. R., Whitney Nicol, C., \& Bredin, S. S. D. (2006). Health benefits of physical activity: The evidence. Canadian Medical Association Journal, 174, 801-809.

White, J., \& Halliwell, E. (2010). Examination of a sociocultural model of excessive exercise among male and female adolescents. Body Image, 7, 227-233. 
Yates, A. (1991). Compulsive exercise and the eating disorders. New York: Brunel/Mazel. 
TABLE 1: Descriptive statistics for study variables and tests of difference (Mann Whitney $U$ ) between boys and girls

Test of

Boys Mean (SD) Girls Mean (SD) Difference

Variable

Z

\begin{tabular}{llll}
\hline mSCIQ More Muscular & $2.38(1.26)$ & $1.46(0.69)$ & $7.83^{\star \star \star}$
\end{tabular}

$\begin{array}{llll}\text { PSPS Media } & 1.59(0.93) & 2.47(1.24) & 7.06^{\star \star \star}\end{array}$

EDI Total

$6.23(6.77)$

$16.74(13.52)$

$8.05^{\star \star \star}$

T2 CET Total

$8.23(3.61)$

9.66 (3.13)

$3.98^{\star \star \star}$

T1 CET Total

8.90 (3.73)

9.56 (3.52)

1.42

Note: $\mathrm{mSCIQ}=$ Modified Sociocultural Influences on Body Image and Body Change

Questionnaire; PSPS = Perceived Sociocultural Pressure Scale; CET = Compulsive

Exercise Test; EDI = Eating Disorder Inventory; T1 = time point 1; T2 = time point 2. $\star \star \star * ~ p<.001$ 
TABLE 2: Hierarchical multiple regression of T2 CET Total score (outcome) for boys, with bootstrapped coefficients.

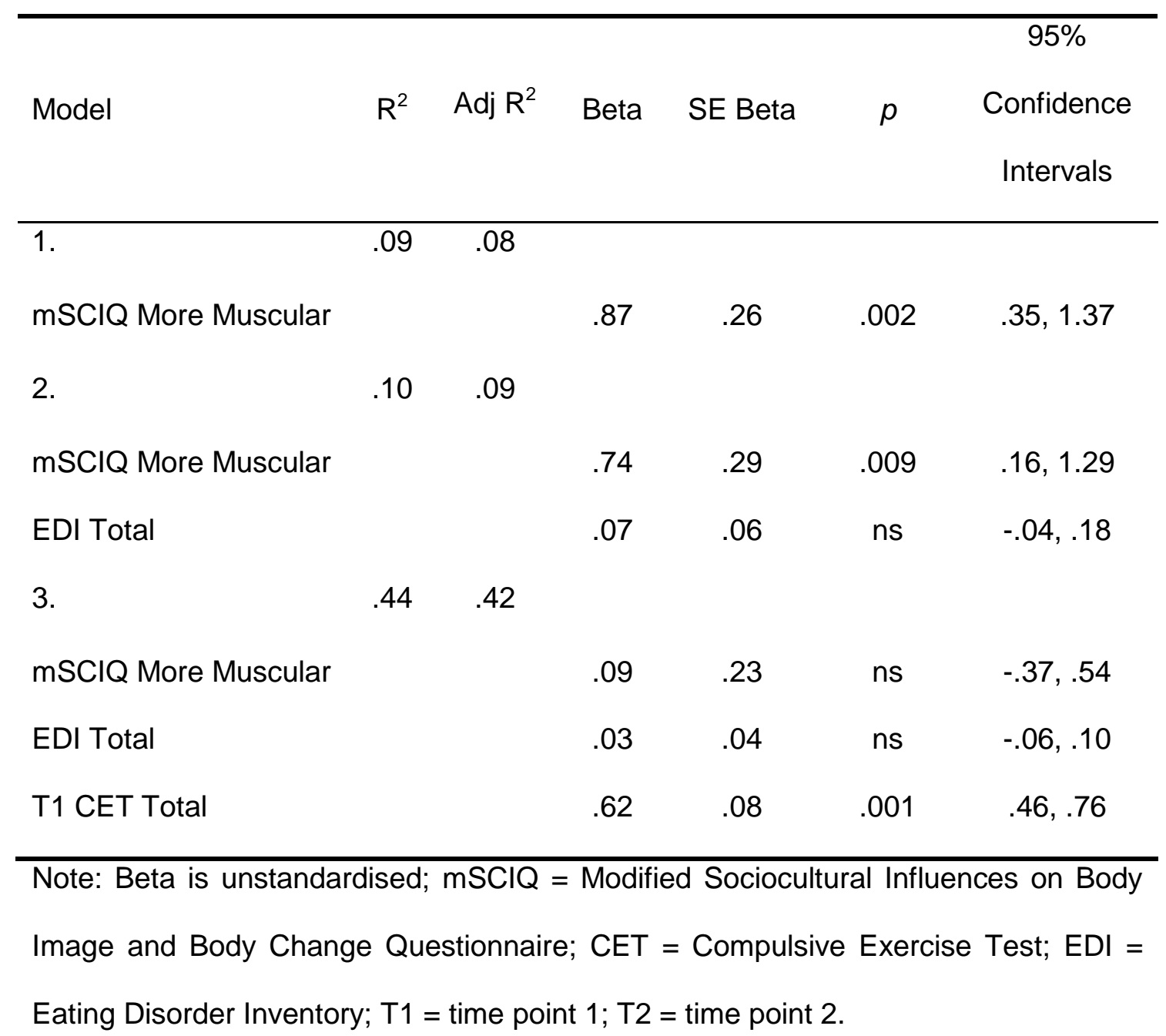


TABLE 3: Hierarchical multiple regression of T2 CET Total score (outcome) for girls, with bootstrapped coefficients.

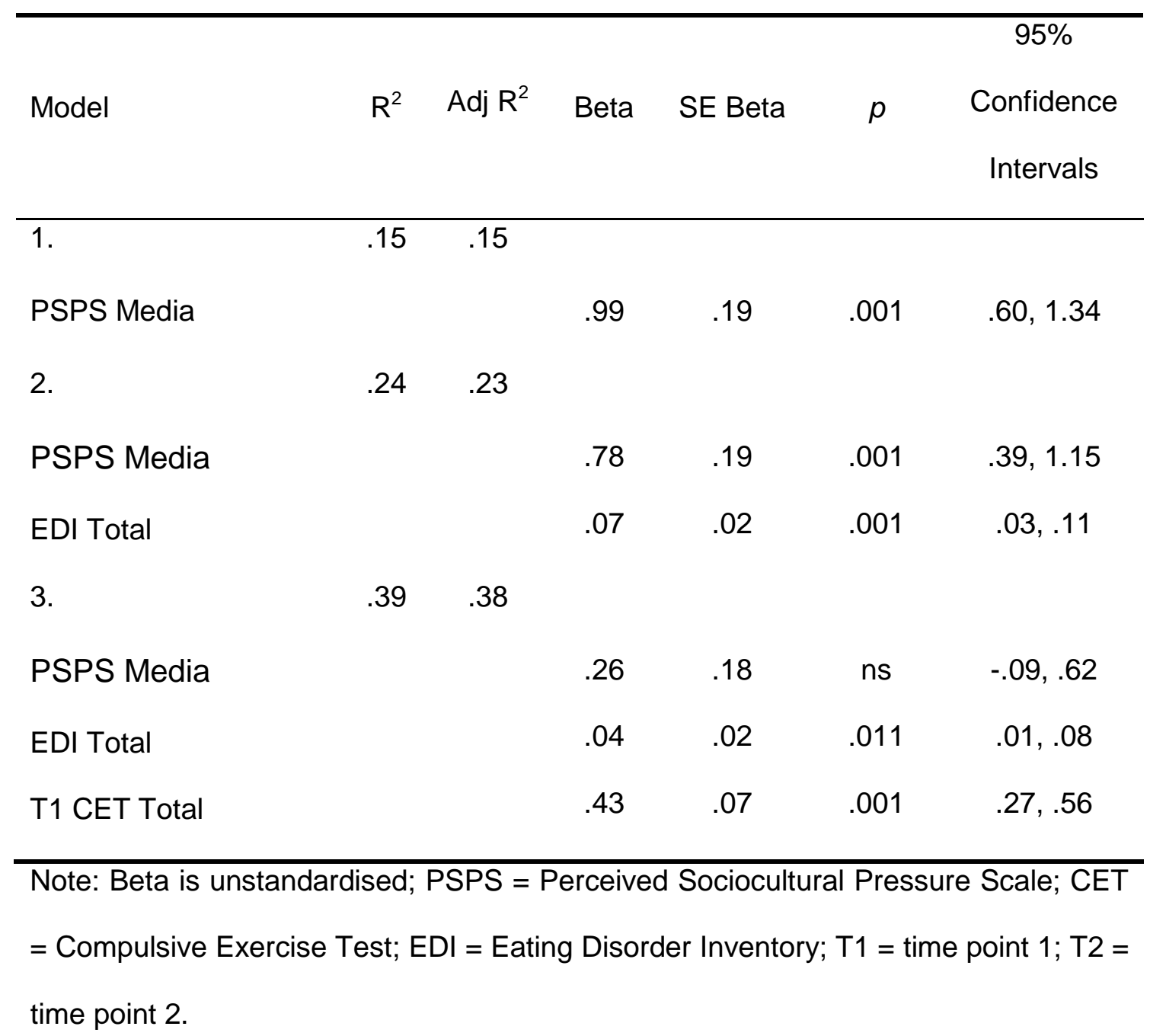

